\title{
Immune Thrombocytopenia in Pregnancy
}

\author{
Evi Stavrou, MD and Keith R. McCrae, MD \\ Division of Hematology-Oncology, Case Western Reserve University School of Medicine, 10900 \\ Euclid Avenue, Cleveland, OH 44106
}

\section{SYNOPSIS}

Management of ITP in pregnancy can be a complex and challenging task, and may be complicated by fetal/neonatal thrombocytopenia. Though fetal intracranial hemorrhage is a rare complication of ITP in pregnancy, invasive studies designed to determine the fetal platelet count before delivery are associated with greater risk than that of fetal intracranial hemorrhage, and therefore are discouraged. Moreover, the risk of neonatal bleeding complications does not correlate with the mode of delivery, and thus cesarean section should be reserved for obstetric indications only.

\section{INTRODUCTION}

Thrombocytopenia complicates up to $10 \%$ of all pregnancies, and may result from a number of causes (Table 1). Some of these are unique to pregnancy, while others may occur with increased frequency during gestation [1-7] and still others bear no relationship to pregnancy per se. While some thrombocytopenic disorders are not associated with adverse pregnancy outcomes, others are associated with significant maternal and/or neonatal morbidity and mortality. The time of onset of these disorders during pregnancy and their clinical manifestations often overlap, making the diagnosis challenging.

Immune thrombocytopenia (ITP) is one of the thrombocytopenic disorders that may complicate pregnancy and it management. This review will focus on the clinical characteristics and management of immune thrombocytopenia in pregnancy, as also include brief discussions on additional thrombocytopenic disorders that may occur in pregnancy and potentially be confused with ITP.

\section{IMMUNE THROMBOCYTOPENIA IN PREGNANCY}

\section{Clinical features}

Immune thrombocytopenia (ITP) [8] occurs in one or two of every 1,000 pregnancies [9], and accounts for $5 \%$ of cases of pregnancy-associated thrombocytopenia. Despite its rarity compared to gestational thrombocytopenia (vide infra), ITP is the most common cause of isolated thrombocytopenia in the first and early second trimesters [3,6,9-11]. The pathophysiology of ITP has been classically believed to reflect the accelerated clearance of platelets coated by IgG anti-platelet autoantibodies. These antibodies recognize specific epitopes expressed on platelet glycoproteins such as glycoprotein IIb/IIIa, or less commonly

\section{(C) 2009 Elsevier Inc. All rights reserved.}

Address all correspondence to: Dr. Keith R. McCrae, 2103 Cornell Road, WRB 2-132, Case Western Reserve University School of Medicine, Cleveland, OH 44106, Phone: 216-368-6606, FAX 216-368-1166, keith.mccrae@case.edu.

Publisher's Disclaimer: This is a PDF file of an unedited manuscript that has been accepted for publication. As a service to our customers we are providing this early version of the manuscript. The manuscript will undergo copyediting, typesetting, and review of the resulting proof before it is published in its final citable form. Please note that during the production process errors may be discovered which could affect the content, and all legal disclaimers that apply to the journal pertain. 
glycoproteins Ib/IX or Ia/IIa [12]. These antibody-coated platelets are then removed following binding to macrophage Fc $\gamma$ receptors, primarily in the spleen [9,13-16]. Some antiplatelet antibodies may also directly activate complement [17]. However, recent studies indicate that several other mechanisms also contribute to the pathogenesis of ITP, including diminished platelet production $[18,19]$, caused at least in part by antibodies that cross react with megakaryocytes [19], and alterations in T cell subsets, in particular loss of regulatory T (Treg) cells [20]. Whether the role of any of these mechanisms is of particular importance in the setting of pregnancy has not been determined.

The presentation of ITP in pregnancy is much like that in the non-pregnant individual. Patients may be diagnosed following the detection of asymptomatic thrombocytopenia on routine testing, or less commonly with more severe thrombocytopenia accompanied by bruising, bleeding, and petechiae. ITP that predates pregnancy may either worsen or remain quiescent during gestation [21,22]. One study that reviewed the experience of 92 women with ITP during 119 pregnancies over an 11 year period found that women with previously diagnosed ITP were less likely to require therapy for ITP than those with newly diagnosed ITP [23].

\section{Diagnosis}

As in the non-pregnant state, the diagnosis of ITP is a clinical diagnosis of exclusion. The likelihood that a patient suffers from ITP rather than incidental thrombocytopenia of pregnancy (vide infra) increases as the platelet count decreases; however, no specific platelet count below which incidental thrombocytopenia may be excluded has been defined. Furthermore, since many patients with apparent incidental thrombocytopenia have elevated levels of plateletassociated IgG, platelet antibody tests do not differentiate these syndromes [24]. In a large study utilizing the monoclonal antibody-specific immobilization of platelet-antigens (MAPA) assay, less than $7 \%$ of thrombocytopenic pregnant women were found to have autoantibodies, and there was no significant difference in the prevalence of autoantibodies between thrombocytopenic and non-thrombocytopenic pregnant women [24-27]. Thus, the most useful means of differentiating these syndromes is, by definition, the antenatal history [28,29]. A history of prior thrombocytopenia, underlying autoimmune disease or severe thrombocytopenia $(<50,000 / \mu \mathrm{l})$ makes the diagnosis of ITP more likely. In the absence of a platelet count prior to pregnancy, significant thrombocytopenia in the first trimester, with a declining platelet count as gestation progresses, is most consistent with ITP. In contrast, mild thrombocytopenia developing in the second or third trimester and not associated with hypertension or proteinuria most likely represents incidental thrombocytopenia[11].

Other relevant questions that should be assessed when evaluating a pregnant patient with thrombocytopenia include whether prior deliveries were complicated by excessive bleeding, and whether the infant had thrombocytopenia or bleeding complications. The physical examination should focus on excluding secondary causes of thrombocytopenia. For example, elevated blood pressure and/or the onset of peripheral edema or weight gain may suggest thrombocytopenia complicating a pregnancy-associated hypertensive disorder [30]. In addition, symptoms potentially consistent with the early development of the HELLP syndrome, such as vague right upper quadrant pain, increasing malaise or unrelenting cephalgia should be specifically sought $[31,32]$. Finally, all thrombocytopenic pregnant patients should be carefully evaluated for the presence of risk factors for HIV and HCV infection [33].

Laboratory investigation of the pregnant patient with suspected ITP should include a complete blood count and platelet count. Examination of the peripheral blood film is essential to exclude not only pseudothrombocytopenia, but other thrombocytopenic disorders such as TTP or preeclampsia, in which the peripheral blood film may reveal increased numbers of fragmented red cells [30]. Other studies that should be considered include liver enzyme tests, urinalysis, and HIV and HCV testing. Bone marrow examination is not recommended unless other 
hematologic abnormalities (other than mild pregnancy-associated anemia) or unusual findings on physical examination are identified. As in non-pregnant individuals, a lack of response to standard ITP therapy in a pregnant patient with thrombocytopenia should prompt consideration of a bone marrow examination.

\section{Maternal management during gestation}

The clinical management of pregnancy-associated ITP is a complex task, requiring close collaboration between the obstetrician and hematologist. Pregnant women with ITP require careful monitoring, and should be seen monthly in the first and second trimester, every 2 weeks after 28 weeks, and weekly after 36 weeks. Visits should involve routine obstetrical care with emphasis on blood pressure, weight, urine dipstick analysis for protein, and serial platelet counts. Decisions concerning the need for therapy are determined primarily by the patient's symptoms, particularly whether active bleeding is present, though the absolute platelet count should be considered as term approaches with the potential need for epidural anesthesia. The $\mathrm{ASH}$ and BCSH guidelines consider treatment to be appropriate for severe thrombocytopenia and/or thrombocytopenia associated with bleeding. However, though there is no evidence to support the opinion that platelet counts should be kept higher in the asymptomatic pregnant woman than in other thrombocytopenic patients [34]. More aggressive treatment is recommended later in pregnancy to prepare the patient for labor and delivery, which often is accompanied by the use of epidural anesthesia.

Treatment has been recommended for women with a platelet count below $10,000 / \mu l$ at any time during pregnancy, or below $30,000 / \mu \mathrm{l}$ in the second or third trimester or when associated with bleeding [16,35-37]. There is lack of consensus in regard to treatment of patients with a platelet count of $<30,000 / \mu 1$ but no bleeding in the first trimester, reflecting the desire to avoid exposure of such patients to corticosteroids during pregnancy $[16,37,38]$. Though treatment of the pregnant woman with ITP generally does not differ significantly from that of non-pregnant individuals, there are some unique considerations [39-42]. Due to their efficacy and low cost, many consider corticosteroids to be first line treatment for ITP in pregnancy $[10,14,36]$. The mechanisms of action of corticosteroids are due, at least in part, to the inhibition of phagocytosis of opsonized platelets, as well as impairment of autoantibody production $[11,43]$. The typical therapeutic dose of prednisone is $1 \mathrm{mg} / \mathrm{kg} / \mathrm{day}$ (based on the pre-pregnancy weight), which, after achieving a response, is gradually titrated to the lowest effective dose. However, the many adverse effects of corticosteroids are amplified during pregnancy, and pregnancy-specific toxicities such as gestational diabetes, weight gain, acceleration of bone loss, hypertension and possibly placental abruption and premature labor must be recognized [7,38]. Furthermore, some studies have associated the use of corticosteroids in the first trimester with congenital anomalies, such as orofacial clefts $[44,45]$. Appreciation of such toxicities might suggest that in the patient in whom therapy is indicated but not urgent, initiation of corticosteroid therapy at a low dose, perhaps $20-30 \mathrm{mg} /$ day of prednisone, should be considered. Alternatively, others have suggested that IVIg should be the first line therapy for pregnancy-associated ITP, especially when a long duration of therapy may not be required [11].

Treatment with high dose (i.e. $2 \mathrm{gm} / \mathrm{kg}$ over $2-5$ days) intravenous immunoglobulin (IVIg) is an effective means of raising the platelet count rapidly. Though the therapeutic effects of IVIg likely reflect a number of mechanisms, a critical requirement for $\mathrm{FcR} \gamma \mathrm{IIb}$, an inhibitory FcR $\gamma$ receptor, has been defined in animal models [46]. Compared to corticosteroids, IVIg is less likely to induce toxicities such as hypertension [23,34]. ASH guidelines consider IVIg to be an appropriate first line agent for severe thrombocytopenia, or thrombocytopenic bleeding in the third trimester [47]. However, responses to IVIg tend to be transient, and multiple courses of therapy may be required at significant cost and patient inconvenience. A subset of patients who fail to respond satisfactorily to corticosteroids or IVIg alone may respond to high doses 
of these agents when administered in combination (methylprednisolone $1 \mathrm{gm}, \mathrm{IVIg} 1-2 \mathrm{gm} / \mathrm{kg}$ ) $[2,10]$.

Splenectomy may be considered as another option for patients who fail to adequately respond to corticosteroids or IVIg. Remission of ITP is initially achieved in approximately $75 \%$ of pregnant women who undergo splenectomy [48]. If required, splenectomy should be performed in the second trimester, as surgery earlier in pregnancy may induce premature labor, and later in pregnancy splenectomy may be technically difficult due to obstruction of the surgical field by the gravid uterus $[2,4]$. Laparoscopic splenectomy can be safely performed in pregnant women [49]. Table 2 summarizes the antepartum management of pregnant women with ITP.

In patients who develop severe ITP refractory to steroids and IVIG, and who are beyond the optimal second trimester window for splenectomy, intravenous anti-D has been used successfully. In one report, 6 of 8 women who received anti-D in their second and third trimester had partial responses, with no major maternal or fetal complications, and no evidence of hydrops [47]. However, experience with this agent in pregnancy is limited, and thus its safety in this setting has not been clearly established.

Other agents used to treat ITP in the non-pregnant population, namely cytotoxic and immunosuppressive agents, are potential teratogens [50-52]. For this reason, danazol, cyclophosphamide and vinca alkaloids should be avoided in pregnancy. Azathioprine is a possible exception that has been used safely in pregnant patients with renal transplants [53-55]. However, neonatal hematologic and immune impairment have been reported in some exposed infants and azathioprine remains a category $\mathrm{D}$ agent. Rituximab has been used in several pregnant patients with lymphoma. No major fetal malformations have been associated with its use [56], though infants born to mothers treated with this agent may experience abnormal B-lymphocyte development in their first year of life. In a few case reports, immunologic recovery was observed at 6 months of life with no infection-related complications [57]. Due to the lack of sufficient evidence of safety, most recommend that Rituximab be avoided in the treatment of pregnancy-associated ITP [58]. Thus, in general, the use of cytotoxic and immunosuppressive agents should be limited to severe cases refractory to other treatments. These agents should be used in the second and third trimesters only and each case should be considered individually.

There is very little experience with either of the thrombopoietic agents in pregnancy, and both are considered category $\mathrm{C}$ for this indication. A pregnancy registry has been developed for patients who become pregnant while taking either Eltrombopag or Romiplostim. Likewise it is not known whether either of these agents are excreted in human milk, and thus their safety in nursing mothers has not been established.

\section{Management of parturition: fetal and maternal considerations}

In managing delivery of the pregnant patient with ITP, some unique issues must be considered. In terms of maternal management, the primary consideration is achieving a platelet count sufficient to minimize maternal hemorrhage not only during vaginal delivery, but in case of cesarean section. Epidural anesthesia is also commonly used during parturition, and adequate hemostasis is required to minimize the risk of any resulting neurologic complications that might arise. The American Society of Hematology guidelines (Table 3), suggest that a maternal platelet count of $50,000 / \mu \mathrm{l}$ is sufficient for vaginal delivery as well as cesarean section. The $\mathrm{BCSH}$ guidelines recommend that a platelet count of $80,000 / \mu \mathrm{l}$ be attained for cesarean delivery as well as for epidural anesthesia, based on a retrospective review in which epidural anesthesia was successfully delivered with no neurologic complications in 30 thrombocytopenic women with platelet counts between $69,000-98,000 / \mu 1$ [59]. Thus, though no prospective, randomized data is available to address this issue definitively, most experts consider a platelet count in the 
range of $80,000 / \mu 1$ adequate for epidural anesthesia and either vaginal delivery or cesarean section in the parturient. Since this may be significantly higher than the therapeutic platelet count range targeted earlier in pregnancy, additional therapy may be required in some pregnant patients as term approaches.

Unique considerations also exist with respect to the fetal platelet count and the risk of intracranial hemorrhage during delivery. Maternal IgG is actively transported to the fetal circulation subsequent to its binding to Fc $\gamma$ receptors on the syncytiotrophoblast cells of the placenta [60-62]. These maternal platelet-reactive antibodies may cross-react with antigens on fetal platelets, leading to the development of fetal thrombocytopenia, which is associated with an increased risk for hemorrhage during delivery. In a large metaanalysis that reviewed series containing 10 or more patients in whom fetal platelet counts were determined, 288 live-born infants were identified. Platelet counts below 50,000/ $\mu$ l were observed in $10.1 \%$ of these infants, while platelet counts below $20,000 / \mu$ occurred in $4.2 \%$ [63].

The most feared consequence of fetal thrombocytopenia is the risk of intracranial hemorrhage, which in theory, has been expected to be increased by head trauma occurring during passage of the fetus through the birth canal during vaginal delivery. Despite this concern, the risk of fetal intracranial hemorrhage in the offspring of patients with ITP is very low. In the metaanalysis noted in the preceding paragraph, no cases of fetal intracranial hemorrhage were observed [63]. In another large observational study, the incidence of intracranial hemorrhage was below $1 \%$ [38]. In this report, the course of 284 mothers with ITP and their 286 newborn infants was described [38]. Neonatal thrombocytopenia (platelet count $<100,000 / \mu \mathrm{l}$ ) was diagnosed in $22.6 \%$ of the offspring, though only $6.3 \%$ experienced bleeding events, and there were no episodes of intracranial hemorrhage. There was no correlation between platelet counts or the ITP status of the mothers and the development of neonatal thrombocytopenia, an observation that has been reported in almost all studies that have examined this issue. Indeed, there is no consistent or reproducible correlation between the fetal platelet count at delivery and a number of maternal characteristics including the severity of maternal thrombocytopenia $[10,11]$, or the level of circulating maternal antiplatelet IgG [29]. Evidence suggests that, of all parameters studied, the most reliable predictor of neonatal thrombocytopenia is a history of thrombocytopenia at delivery in a prior sibling [64].

Due to the inability to predict neonatal thrombocytopenia based on maternal clinical characteristics, invasive procedures such as fetal scalp sampling during labor, or percutaneous umbilical blood sampling (PUBS) have been developed. Fetal scalp vein sampling is technically difficult; platelet counts obtained through this procedure have not been shown to correlate with the platelet count at delivery [65] and may falsely predict thrombocytopenia, possibly due to clotting of blood during sampling. In contrast, PUBS is often able to yield accurate platelet counts, but is associated with complication rates of up to $2 \%$, approximately half of which may necessitate emergent delivery and ultimately result in pregnancy loss [65-67]. Thus, the risks of fetal platelet count determination are at the least equal to, and likely exceed that of fetal intracranial hemorrhage, negating its clinical utility $[34,47,66,68]$.

While it was previously believed that cesarean section reduced the risk of fetal intracranial hemorrhage during delivery of offspring of patients with ITP, studies over the last two decades have demonstrated that this does not appear to be the case [11,69]. In one study, 31 pregnancies in 25 women with ITP over a 10 year period were reviewed [70]. Fourteen infants were born vaginally, and 18 by cesarean, with no complications in any, despite platelet counts below $100,000 / \mu \mathrm{l}$ in 5 infants, and below $50,000 / \mu \mathrm{l}$ in 2 [70]. These authors also reviewed literature reports of 474 infants born to mothers with ITP, finding that platelet counts below $50,000 / \mu 1$ occurred in $15 \%$, and intracranial hemorrhage in $3 \%$. However, no association of intracranial hemorrhage with the mode of delivery was observed [70]. In another retrospective review of 
601 infants of mothers with ITP, severe neonatal thrombocytopenia was reported in 72 (12\%), with relatively equal numbers of these babies being delivered by vaginal delivery $(n=307)$ or cesarean section $(n=247)$. Six infants developed intracranial hemorrhage, two of which were delivered by cesarean section. Four of these six infants had severe neonatal thrombocytopenia $[29,65,66,70-81]$. Thus, given the fact that neonatal intracranial hemorrhage is an extremely rare complication of maternal ITP [65], and that cesarean deliveries may be associated with significant maternal morbidity, it is generally recommended that cesarean section be performed solely for maternal indications.

Following delivery, serial platelet counts should be obtained in all newborns at birth and during the first week postpartum, because the onset of thrombocytopenia due to maternal anti-platelet $\mathrm{IgG}$ may be delayed. In a study of 61 infants born to ITP mothers, $66 \%$ of neonates experienced a further fall in their platelet counts after birth, with $54 \%$ reaching their nadir by day 2 . The platelet count stabilized or began to rise by day 7 in all infants [76]. ASH guidelines suggest that infants with a platelet count below 20,000/ $\mu 1$, or those with hemorrhage, receive treatment. IVIg at a dose of $1 \mathrm{gm} / \mathrm{kg}$ is effective in inducing a prompt rise in the platelet count; the concurrent use of corticosteroids is controversial due to a possible predisposition to neonatal sepsis. Imaging of the brain with ultrasonography, computed tomography or magnetic resonance should be performed in all newborns with platelet counts of less than 50,000/ $\mu 1$ to exclude the possibility of occult intracranial hemorrhage that may require prompt intervention. Finally, women with ITP should not be discouraged from breast feeding, as there has been no firm association established between breast feeding and neonatal thrombocytopenia [43].

\section{OTHER CAUSES OF THROMBOCYTOPENIA IN PREGNANCY}

As discussed above, the differential diagnosis of ITP in a pregnant patient is wide, certainly much larger than in the non-pregnant setting. Determining the appropriate diagnosis with the greatest degree of certainty is essential to initiating appropriate therapy. Thus, an understanding of other causes of thrombocytopenia in pregnancy is useful in differentiating these from ITP, and will be discussed briefly below.

\section{Gestational "incidental” thrombocytopenia}

Population-based studies demonstrate that a physiologic decline in the platelet count of approximately $10 \%$ occurs during uncomplicated pregnancy, with the decline being greatest in the third trimester [82]. Despite this decrease, however, the platelet count usually remains in the normal range throughout gestation [3,10]. Gestational or "incidental" thrombocytopenia of pregnancy may represent a more severe variant of this physiologic thrombocytopenia, although its pathogenesis is not well defined.

Gestational thrombocytopenia is the most common cause of thrombocytopenia in pregnancy, affecting $5 \%$ of all pregnancies and accounting for more than $75 \%$ of cases of pregnancyassociated thrombocytopenia $[4,6,10,25,83-85]$. This disorder usually develops in the late second or third trimester and generally affects women with no prior history of ITP or autoimmune disease. It is characterized by mild thrombocytopenia not accompanied by abnormal physical findings, such as hypertension, that would implicate other causes of thrombocytopenia. While no absolute value of the platelet count below which gestational thrombocytopenia can be excluded has been defined, the American Society of Hematology (ASH) as well as the British Committee for Standard in Hematology General Hematology Task Force (BCSH) suggest that at platelet counts below $70,000 / \mu 1$ or $80,000 / \mu 1$, respectively, gestational thrombocytopenia becomes increasingly less likely and other causes of thrombocytopenia should be more strongly considered $[36,37]$. 
Gestational thrombocytopenia is not associated with an increased incidence of pregnancyrelated complications or the delivery of thrombocytopenic offspring $[2,4,6,25,83,84]$. Thus, evaluation of healthy pregnant women with no history of prior thrombocytopenia and a platelet count greater than $70,000 / \mu \mathrm{l}$ may be limited to a physical examination and a thorough inspection of the peripheral blood film [35]. Confirmation of a normal platelet count prior to pregnancy may also be very useful in diagnosing this disorder [37]. However, some of the more severe cases of gestational thrombocytopenia cannot be reliably distinguished from mild cases of ITP $[1,23]$, as platelet counts in these two disorders overlap and patients with either disorder may be otherwise asymptomatic.

\section{Preeclampsia and the HELLP syndrome}

Preeclampsia affects 3 to $14 \%$ of pregnancies and is the most common medical disorder of pregnancy [86]. In contrast to ITP, preeclampsia usually occurs in the third trimester [86,87] affecting women less than 20 or greater than 30 years of age $[88,89]$. The criteria for preeclampsia include hypertension (systolic $\mathrm{BP} \geq 140 \mathrm{~mm} \mathrm{Hg}$, diastolic $\mathrm{BP} \geq 90 \mathrm{~mm} \mathrm{Hg}$ ) and proteinuria ( $>300 \mathrm{mg}$ protein/24h) developing after 20 weeks of gestation [89]. A genetic role in the development of preeclampsia is likely, but remains incompletely defined [90]; some studies demonstrate paternal as well as maternal genetic influences [90].

Thrombocytopenia develops in approximately $50 \%$ of patients with preeclampsia, and may precede other manifestations [10]. Thus, despite this complex constellation of symptoms, thrombocytopenia may occasionally be the presenting manifestation of preeclampsia, and thus preeclampsia should be considered in patients presenting with isolated thrombocytopenia, particularly during the later stages of pregnancy. The mechanisms of thrombocytopenia in patients with preeclampsia and thrombocytopenia are uncertain, but the presence of normal to increased numbers of megakaryocytes in these patients suggest that this results from a compensated thrombocytolytic state [91].

The pathogenesis of preeclampsia is poorly understood, but several studies have demonstrated that it is initiated and mediated by factors within the placenta [92-94]. Placentation, the process by which fetal trophoblasts invade the endometrium and remodel the uterine vasculature, appears to be disordered [95-97]. Abnormalities in the expression of cell adhesion molecules [98], vascular endothelial growth factor (VEGF), and VEGF receptors by trophoblasts have been described [10]. The net result of such a process is the development of fetoplacental ischemia [93], which leads to impaired release and metabolism of prostaglandins [4]. The diminished production of prostacyclin $\left(\mathrm{PGI}_{2}\right), \mathrm{PGE}_{2}$, and the augmented production of thromboxane $\left(\mathrm{TXA}_{2}\right)$ and $\mathrm{PGF}_{2} \alpha$ have been reported to contribute to the development of hypertension, reduced placental flow and platelet activation [92,99].

The HELLP syndrome is often considered to be a variant of preeclampsia. It occurs in about 0.5 to $0.9 \%$ of all pregnancies and in 10 to $20 \%$ of cases with severe preeclampsia $[100,101]$. Like preeclampsia, most cases occur in the third trimester with about $10 \%$ occurring before the $27^{\text {th }}$ week, and $20 \%$ beyond the $37^{\text {th }}$ gestational week [102]. This disorder occurs primarily in white, multiparous women above the age of 25 years who present with nausea, malaise and right upper quadrant pain and/or epigastric pain $[32,103,104]$. The triad of microangiopathic hemolytic anemia (MAHA), abnormal liver function (SGOT $\geq 70 \mathrm{U} / \mathrm{L}$ ), and thrombocytopenia with a platelet count less than 100,000/ $\mu$ l constitutes the diagnostic criteria of HELLP [105]. Other signs suggestive of hemolysis include an elevated LDH ( $\geq 600 \mathrm{IU} / \mathrm{L})$, and increased bilirubin levels ( $\geq 1.2 \mathrm{mg} / \mathrm{dL}$ ). Unlike preeclampsia, proteinuria is generally minimal or absent [106]. Despite their similarities, HELLP is associated with significantly greater maternal and fetal morbidity and mortality than preeclampsia [107]. This symptom profile should generally allow one to distinguish HELLP from ITP with relative certainty, although as with preeclampsia, thrombocytopenia may be an early presenting feature of HELLP. 
The overall approach to management of either of these syndromes involves medical stabilization of the patient, followed by delivery of the fetus [106-108]. Because most cases of preeclampsia and HELLP develop after 34 weeks of gestation, by which time the fetal lung has adequately matured [80], immediate delivery is considered to be the definite treatment. Therapy in the setting of severe thrombocytopenia and bleeding may require platelet transfusion; however, since the mechanism of thrombocytopenia in these cases is accelerated platelet destruction, survival of transfused platelets is short [107].

\section{Thrombotic thrombocytopenic purpura and the hemolytic uremic syndrome}

Thrombotic thrombocytopenic purpura (TTP) and hemolytic uremic syndrome (HUS) are characterized by microangiopathic hemolytic anemia (MAHA) and thrombocytopenia. Although neither disease is unique to pregnancy, the incidence of these disorders is clearly increased in pregnant women.

TTP is characterized by a pentad of findings that include MAHA, thrombocytopenia, neurologic abnormalities (including confusion, headache, weakness and, in some cases, seizures), fever and renal dysfunction $[4,10]$. However, this complete set of symptoms occurs in only $40 \%$ of patients, and more than $70 \%$ have only the triad of MAHA, thrombocytopenia and neurologic changes at the time of diagnosis $[4,109]$. The clinical manifestations of HUS are similar, though often predominated by renal abnormalities as opposed to neurologic abnormalities in patients with TTP [110]. Thus, in a patient exhibiting the full spectrum of abnormalities associated with TTP or HUS, distinction from ITP should be straightforward, though as with preeclampsia and HELLP, thrombocytopenia may be a predominant early finding that should lead the clinician to look for accompanying manifestations such as MAHA, renal dysfunction and subtle neurologic abnormalities. Discriminating features between these disorders are listed in Table 4.

The pathogenesis of TTP involves the congenital or acquired deficiency of the vWF-cleaving protease [110-114] ADAMTS13. Levels of ADAMTS13 are markedly decreased in patients with TTP, usually secondary to antibodies against the proteases $[113,115]$, or more rarely, a congenital deficiency due to mutation of the ADAMTS13 gene [111]. HUS may present with a variety of manifestations, with one variant occurring after Escherichia coli O157:H7 gastroenteritis, primarily in children [116]. However, in adults, HUS occurs most commonly in association with pregnancy, with more than $90 \%$ of cases developing in the postpartum period [117].

\section{Miscellaneous causes of thrombocytopenia in pregnancy}

In addition to the disorders described in the paragraphs above, other obstetrical entities such as amniotic fluid embolism [118], placental abruption [119], uterine rupture [120], and retention of a dead fetus [121] may be associated with DIC, which can induce a consumptive thrombocytopenia.

Acute fatty liver of pregnancy (AFLP) typically presents in primiparas between the $30^{\text {th }}$ and $38^{\text {th }}$ gestational weeks [122] with a 1 to 2 week history of malaise, anorexia, nausea, vomiting, epigastric or right upper quadrant pain, mental status changes, and cholestatic liver abnormalities. Laboratory examination reveals hemoconcentration, metabolic acidosis, mild thrombocytopenia, and low grade DIC with low serum fibrinogen, low antithrombin and prolonged prothrombin time (PT) [110,122].

Although not unique to pregnancy, drug-induced thrombocytopenia should always be considered when evaluating a pregnant patient with low platelet counts. Of note, acute cocaine 
ingestion has been associated with a syndrome resembling HELLP, and may be accompanied by the transient development of profound thrombocytopenia [123].

Pseudothrombocytopenia, an in vitro artifact attributable to platelet clumping caused by EDTA-dependent antiplatelet antibodies, may be transferred from the mother to fetus due to transplacental passage of the antibodies.

Systemic lupus erythematosus (SLE) is the collagen-vascular disorder most commonly compromising pregnancy [124]. Thrombocytopenia occurs in approximately 15 to $26 \%$ of patients with SLE, and results from increased peripheral platelet destruction induced by antiplatelet antibodies and/or circulating immune complexes ("secondary" ITP) [125]. In addition, approximately $25 \%$ of patients with SLE have antiphospholipid antibodies, which have been associated with both thrombocytopenia [126] and preeclampsia [127].

HIV or hepatitis $\mathrm{C}$-associated thrombocytopenia should be considered in any pregnant woman and may be initially diagnosed during pregnancy. Finally, type IIb vWD is an unusual cause of thrombocytopenia in pregnancy, in which the estrogen-rich environment induces an increased production of vWF, which in the case of the type IIb vWD variant may further accelerate platelet clearance $[128,129]$.

\section{CONCLUSIONS}

ITP is an uncommon, but important cause of thrombocytopenia in pregnancy. Though most commonly presenting in the first trimester, ITP may present at any point during gestation. Though ITP is associated with a significant incidence of neonatal thrombocytopenia, it is generally not associated with major morbidity if properly managed. IVIg and low-dose corticosteroids comprise the mainstays of treatment in ITP, but high doses of corticosteroids or prolonged corticosteroid therapy are associated with significant toxicity in the pregnant patient and should be avoided. Despite the development of severe thrombocytopenia in approximately $5-10 \%$ of the offspring of patients with ITP, the incidence of neonatal intracranial hemorrhage in these individuals is extremely low. Thus, invasive procedures for establishing the fetal platelet count are associated with a degree of risk that likely exceeds that of fetal intracranial hemorrhage, and are not indicated in most cases. Moreover, delivery by cesarean section has not been shown to decrease the risk of neonatal intracranial hemorrhage compared to vaginal delivery, and thus the mode of delivery in pregnant patients with ITP should be solely dictated by maternal factors.

The diagnosis of ITP in pregnancy is complicated by a wide differential diagnosis that includes several other disorders that can cause thrombocytopenia in this setting. Gestational or "incidental" thrombocytopenia remains the most common cause of thrombocytopenia in pregnancy, accounting for approximately $75 \%$ of cases, and may be impossible to distinguish from mild ITP. However, gestational thrombocytopenia is not associated with adverse maternal or fetal outcomes. Preeclampsia, the HELLP syndrome, and TTP/HUS are other disorders that may cause thrombocytopenia in pregnancy. These disorders are generally not difficult to distinguish from ITP, but in some individuals the presenting feature may be thrombocytopenia, and thus these disorders should be considered in any pregnant patient with a low platelet count. Meticulous attention to accurate diagnosis of these disorders generally allows them to be separated from ITP, and is critical for their successful management.

\section{References}

1. McCrae, K. Thrombocytopenia in Pregnancy. In: Michelson, A., editor. Platelets. New York, NY: Elsevier; 2006. 
2. McCrae KR. Thrombocytopenia in pregnancy: differential diagnosis, pathogenesis, and management. Blood Rev 2003;17(1):7. [PubMed: 12490206]

3. McCrae KR, Bussel JB, Mannucci PM, et al. Platelets: an update on diagnosis and management of thrombocytopenic disorders. Hematology Am Soc Hematol Educ Program 2001:282. [PubMed: 11722989]

4. McCrae KR, Cines DB. Thrombotic microangiopathy during pregnancy. Semin Hematol 1997;34(2): 148. [PubMed: 9109217]

5. McMinn JR, George JN. Evaluation of women with clinically suspected thrombotic thrombocytopenic purpura-hemolytic uremic syndrome during pregnancy. J Clin Apher 2001;16(4):202. [PubMed: 11835417]

6. Crowther MA, Burrows RF, Ginsberg J, et al. Thrombocytopenia in pregnancy: diagnosis, pathogenesis and management. Blood Rev 1996;10(1):8. [PubMed: 8861274]

7. Kelton JG. Idiopathic thrombocytopenic purpura complicating pregnancy. Blood Rev 2002;16(1):43. [PubMed: 11913994]

8. Cines DB, Bussel JB, Liebman HA, et al. The ITP syndrome: pathogenic and clinical diversity. Blood. 2009

9. Provan D, Newland A. Idiopathic thrombocytopenic purpura in adults. J Pediatr Hematol Oncol 2003;25(Suppl 1):S34. [PubMed: 14668637]

10. McCrae KR, Samuels P, Schreiber AD. Pregnancy-associated thrombocytopenia: pathogenesis and management. Blood 1992;80(11):2697. [PubMed: 1450402]

11. Gill KK, Kelton JG. Management of idiopathic thrombocytopenic purpura in pregnancy. Semin Hematol 2000;37(3):275. [PubMed: 10942222]

12. McMillan R. Immune-mediated thrombocytopenias: focus on chronic immune thrombocytopenic purpura. Semin Hematol 2007;44(4 Suppl 5):S1. [PubMed: 18096467]

13. Baldini M. Idiopathic thrombocytopenic purpura. N Engl J Med 1966;274(24):1360. [PubMed: 5949067]

14. Cines DB, Blanchette VS. Immune thrombocytopenic purpura. N Engl J Med 2002;346(13):995. [PubMed: 11919310]

15. Harrington WJ, Minnich V, Hollingsworth JW, et al. Demonstration of a thrombocytopenic factor in the blood of patients with thrombocytopenic purpura. J Lab Clin Med 1951;38(1):1. [PubMed: 14850832]

16. Cines DB, McMillan R. Management of adult idiopathic thrombocytopenic purpura. Annu Rev Med 2005;56:425. [PubMed: 15660520]

17. Cines DB, Schreiber AD. Immune thrombocytopenia. Use of a Coombs antiglobulin test to detect IgG and C3 on platelets. N Engl J Med 1979;300(3):106. [PubMed: 569254]

18. Chang M, Nakagawa PA, Williams SA, et al. Immune thrombocytopenic purpura (ITP) plasma and purified ITP monoclonal autoantibodies inhibit megakaryocytopoiesis in vitro. Blood 2003;102(3): 887. [PubMed: 12676790]

19. McMillan R, Wang L, Tomer A, et al. Suppression of in vitro megakaryocyte production by antiplatelet autoantibodies from adult patients with chronic ITP. Blood 2004;103(4):1364. [PubMed: 14576051]

20. McMillan R. The pathogenesis of chronic immune thrombocytopenic purpura. Semin Hematol 2007;44(4 Suppl 5):S3. [PubMed: 18096470]

21. Devendra K, Koh LP. Pregnancy in women with idiopathic thrombocytopaenic purpura. Ann Acad Med Singapore 2002;31(3):276. [PubMed: 12061285]

22. Won YW, Moon W, Yun YS, et al. Clinical aspects of pregnancy and delivery in patients with chronic idiopathic thrombocytopenic purpura (ITP). Korean J Intern Med 2005;20(2):129. [PubMed: 16134767]

23. Webert KE, Mittal R, Sigouin C, et al. A retrospective 11-year analysis of obstetric patients with idiopathic thrombocytopenic purpura. Blood 2003;102(13):4306. [PubMed: 12947011]

24. Boehlen F, Hohlfeld P, Extermann P, et al. Maternal antiplatelet antibodies in predicting risk of neonatal thrombocytopenia. Obstet Gynecol 1999;93(2):169. [PubMed: 9932549] 
25. Shehata N, Burrows R, Kelton JG. Gestational thrombocytopenia. Clin Obstet Gynecol 1999;42(2): 327. [PubMed: 10370851]

26. Sainio S, Kekomaki R, Riikonen S, et al. Maternal thrombocytopenia at term: a population-based study. Acta Obstet Gynecol Scand 2000;79(9):744. [PubMed: 10993097]

27. Samuels P, Main EK, Tomaski A, et al. Abnormalities in platelet antiglobulin tests in preeclamptic mothers and their neonates. Am J Obstet Gynecol 1987;157(1):109. [PubMed: 3496793]

28. Burrows RF, Kelton JG. Incidentally detected thrombocytopenia in healthy mothers and their infants. N Engl J Med 1988;319(3):142. [PubMed: 3386694]

29. Samuels P, Bussel JB, Braitman LE, et al. Estimation of the risk of thrombocytopenia in the offspring of pregnant women with presumed immune thrombocytopenic purpura. N Engl J Med 1990;323(4): 229. [PubMed: 2366833]

30. Pridjian G, Puschett JB. Preeclampsia. Part 1: clinical and pathophysiologic considerations. Obstet Gynecol Surv 2002;57(9):598. [PubMed: 12218668]

31. O'Brien JM, Barton JR. Controversies with the diagnosis and management of HELLP syndrome. Clin Obstet Gynecol 2005;48(2):460. [PubMed: 15805802]

32. Barton JR, Sibai BM. Diagnosis and management of hemolysis, elevated liver enzymes, and low platelets syndrome. Clin Perinatol 2004;31(4):807. [PubMed: 15519429]

33. Nardi M, Karpatkin S. Antiidiotype antibody against platelet anti-GPIIIa contributes to the regulation of thrombocytopenia in HIV-1-ITP patients. J Exp Med 2000;191(12):2093. [PubMed: 10859334]

34. Ajzenberg N, Dreyfus M, Kaplan C, et al. Pregnancy-associated thrombocytopenia revisited: assessment and follow-up of 50 cases. Blood 1998;92(12):4573. [PubMed: 9845523]

35. Letsky EA, Greaves M. Guidelines on the investigation and management of thrombocytopenia in pregnancy and neonatal alloimmune thrombocytopenia. Maternal and Neonatal Haemostasis Working Party of the Haemostasis and Thrombosis Task Force of the British Society for Haematology. Br J Haematol 1996;95(1):21. [PubMed: 8857933]

36. George JN, Woolf SH, Raskob GE, et al. Idiopathic thrombocytopenic purpura: a practice guideline developed by explicit methods for the American Society of Hematology. Blood 1996;88(1):3. [PubMed: 8704187]

37. Guidelines for the investigation and management of idiopathic thrombocytopenic purpura in adults, children and in pregnancy. British Journal of Haematology 2003;120(4):574. [PubMed: 12588344]

38. Fujimura K, Harada Y, Fujimoto T, et al. Nationwide study of idiopathic thrombocytopenic purpura in pregnant women and the clinical influence on neonates. Int J Hematol 2002;75(4):426. [PubMed: 12041677]

39. Kelton JG. Management of the pregnant patient with idiopathic thrombocytopenic purpura. Ann Intern Med 1983;99(6):796. [PubMed: 6359999]

40. Carloss HW, McMillan R, Crosby WH. Management of pregnancy in women with immune thrombocytopenic purpura. JAMA 1980;244(24):2756. [PubMed: 7192327]

41. Moise KJ Jr. Autoimmune thrombocytopenic purpura in pregnancy. Clin Obstet Gynecol 1991;34 (1):51. [PubMed: 2025976]

42. Kessler I, Lancet M, Borenstein R, et al. The obstetrical management of patients with immunologic thrombocytopenic purpura. Int J Gynaecol Obstet 1982;20(1):23. [PubMed: 6126403]

43. Christiaens GC, Nieuwenhuis HK, von dem Borne AE, et al. Idiopathic thrombocytopenic purpura in pregnancy: a randomized trial on the effect of antenatal low dose corticosteroids on neonatal platelet count. Br J Obstet Gynaecol 1990;97(10):893. [PubMed: 2223679]

44. Kallen B. Maternal drug use and infant cleft lip/palate with special reference to corticoids. Cleft Palate Craniofac J 2003;40(6):624. [PubMed: 14577813]

45. Pradat P, Robert-Gnansia E, Di Tanna GL, et al. First trimester exposure to corticosteroids and oral clefts. Birth Defects Res A Clin Mol Teratol 2003;67(12):968. [PubMed: 14745915]

46. Teeling JL, Jansen-Hendriks T, Kuijpers TW, et al. Therapeutic efficacy of intravenous immunoglobulin preparations depends on the immunoglobulin $\mathrm{G}$ dimers: studies in experimental immune thrombocytopenia. Blood 2001;98(4):1095. [PubMed: 11493456]

47. Cines DB, Bussel JB. How I treat idiopathic thrombocytopenic purpura (ITP). Blood 2005;106(7): 2244. [PubMed: 15941913] 
48. Bussel JB. Splenectomy-sparing strategies for the treatment and long-term maintenance of chronic idiopathic (immune) thrombocytopenic purpura. Semin Hematol 2000;37(1 Suppl 1):1. [PubMed: 10676916]

49. Griffiths J, Sia W, Shapiro AM, et al. Laparoscopic splenectomy for the treatment of refractory immune thrombocytopenia in pregnancy. J Obstet Gynaecol Can 2005;27(8):771. [PubMed: 16287009]

50. Bar Oz B, Hackman R, Einarson T, et al. Pregnancy outcome after cyclosporine therapy during pregnancy: a meta-analysis. Transplantation 2001;71(8):1051. [PubMed: 11374400]

51. Cote CJ, Meuwissen HJ, Pickering RJ. Effects on the neonate of prednisone and azathioprine administered to the mother during pregnancy. J Pediatr 1974;85(3):324. [PubMed: 4372551]

52. Herold M, Schnohr S, Bittrich H. Efficacy and safety of a combined rituximab chemotherapy during pregnancy. J Clin Oncol 2001;19(14):3439. [PubMed: 11454895]

53. Marushak A, Weber T, Bock J, et al. Pregnancy following kidney transplantation. Acta Obstet Gynecol Scand 1986;65(6):557. [PubMed: 3541482]

54. Brown JH, Maxwell AP, McGeown MG. Outcome of pregnancy following renal transplantation. Ir J Med Sci 1991;160(8):255. [PubMed: 1938314]

55. Bar J, Stahl B, Hod M, et al. Is immunosuppression therapy in renal allograft recipients teratogenic? A single-center experience. Am J Med Genet A 2003;116A(1):31. [PubMed: 12476448]

56. Ojeda-Uribe M, Gilliot C, Jung G, et al. Administration of rituximab during the first trimester of pregnancy without consequences for the newborn. J Perinatol 2006;26(4):252. [PubMed: 16570081]

57. Klink DT, van Elburg RM, Schreurs MW, et al. Rituximab administration in third trimester of pregnancy suppresses neonatal B-cell development. Clin Dev Immunol 2008;2008:271363. [PubMed: 18596903]

58. Kimby E, Sverrisdottir A, Elinder G. Safety of rituximab therapy during the first trimester of pregnancy: a case history. Eur J Haematol 2004;72(4):292. [PubMed: 15089769]

59. Beilin Y, Zahn J, Comerford M. Safe epidural analgesia in thirty parturients with platelet counts between 69,000 and 98,000 mm(-3). Anesth Analg 1997;85(2):385. [PubMed: 9249118]

60. Schlamowitz M. Membrane receptors in the specific transfer of immunoglobulins from mother to young. Immunol Commun 1976;5(6):481. [PubMed: 825445]

61. Leach L, Eaton BM, Firth JA, et al. Immunogold localisation of endogenous immunoglobulin-G in ultrathin frozen sections of the human placenta. Cell Tissue Res 1989;257(3):603. [PubMed: 2507158]

62. Stuart SG, Simister NE, Clarkson SB, et al. Human IgG Fc receptor (hFcRII; CD32) exists as multiple isoforms in macrophages, lymphocytes and IgG-transporting placental epithelium. EMBO J 1989;8 (12):3657. [PubMed: 2531080]

63. Burrows RF, Kelton JG. Pregnancy in patients with idiopathic thrombocytopenic purpura: assessing the risks for the infant at delivery. Obstet Gynecol Surv 1993;48(12):781. [PubMed: 8309660]

64. CHRISTIAENS GCML, NIEUWENHUIS HK, BUSSEL JB. Comparison of Platelet Counts in First and Second Newborns of Mothers With Immune Thrombocytopenic Purpura. Obstetrics \& Gynecology 1997;90(4 Part 1):546. [PubMed: 9380314]

65. Payne SD, Resnik R, Moore TR, et al. Maternal characteristics and risk of severe neonatal thrombocytopenia and intracranial hemorrhage in pregnancies complicated by autoimmune thrombocytopenia. Am J Obstet Gynecol 1997;177(1):149. [PubMed: 9240599]

66. Garmel SH, Craigo SD, Morin LM, et al. The role of percutaneous umbilical blood sampling in the management of immune thrombocytopenic purpura. Prenat Diagn 1995;15(5):439. [PubMed: 7644433]

67. Christiaens GC. Immune thrombocytopenic purpura in pregnancy. Baillieres Clin Haematol 1998;11 (2):373. [PubMed: 10097814]

68. Song TB, Lee JY, Kim YH, et al. Low neonatal risk of thrombocytopenia in pregnancy associated with immune thrombocytopenic purpura. Fetal Diagn Ther 1999;14(4):216. [PubMed: 10420044]

69. Cines DB, Bussel JB. How I treat idiopathic thrombocytopenic purpura (ITP). Blood 2005;106(7): 2244. [PubMed: 15941913] 
70. Cook RL, Miller RC, Katz VL, et al. Immune thrombocytopenic purpura in pregnancy: a reappraisal of management. Obstet Gynecol 1991;78(4):578. [PubMed: 1923158]

71. Territo M, Finklestein J, Oh W, et al. Management of autoimmune thrombocytopenia in pregnancy and in the neonate. Obstet Gynecol 1973;41(4):579. [PubMed: 4540509]

72. Jones RW, Asher MI, Rutherford CJ, et al. Autoimmune (idiopathic) thrombocytopenic purpura in pregnancy and the newborn. Br J Obstet Gynaecol 1977;84(9):679. [PubMed: 562177]

73. Scott JR, Cruikshank DP, Kochenour NK, et al. Fetal platelet counts in the obstetric management of immunologic thrombocytopenic purpura. Am J Obstet Gynecol 1980;136(4):495. [PubMed: 7188833]

74. Moise KJ Jr, Carpenter RJ Jr, Cotton DB, et al. Percutaneous umbilical cord blood sampling in the evaluation of fetal platelet counts in pregnant patients with autoimmune thrombocytopenia purpura. Obstet Gynecol 1988;72(3 Pt 1):346. [PubMed: 3405549]

75. Scioscia AL, Grannum PA, Copel JA, et al. The use of percutaneous umbilical blood sampling in immune thrombocytopenic purpura. Am J Obstet Gynecol 1988;159(5):1066. [PubMed: 3189439]

76. Burrows RF, Kelton JG. Low fetal risks in pregnancies associated with idiopathic thrombocytopenic purpura. Am J Obstet Gynecol 1990;163(4 Pt 1):1147. [PubMed: 2101589]

77. Kelton JG, Inwood MJ, Barr RM, et al. The prenatal prediction of thrombocytopenia in infants of mothers with clinically diagnosed immune thrombocytopenia. Am J Obstet Gynecol 1982;144(4): 449. [PubMed: 7124865]

78. Moutet A, Fromont P, Farcet JP, et al. Pregnancy in women with immune thrombocytopenic purpura. Arch Intern Med 1990;150(10):2141. [PubMed: 2222099]

79. Karpatkin M, Porges RF, Karpatkin S. Platelet counts in infants of women with autoimmune thrombocytopenia: effects of steroid administration to the mother. N Engl J Med 1981;305(16):936. [PubMed: 7196991]

80. Laros RK, Sweet RL. Management of idiopathic thrombocytopenic purpura during pregnancy. Am J Obstet Gynecol 1975;122(2):182. [PubMed: 1171620]

81. Wahbeh CJ, Eden RD, Killam AP, et al. Pregnancy and immune thrombocytopenic purpura. Am J Obstet Gynecol 1984;149(2):238. [PubMed: 6539074]

82. Verdy E, Bessous V, Dreyfus M, et al. Longitudinal analysis of platelet count and volume in normal pregnancy. Thromb Haemost 1997;77(4):806. [PubMed: 9134665]

83. Burrows RF, Kelton JG. Fetal thrombocytopenia and its relation to maternal thrombocytopenia. N Engl J Med 1993;329(20):1463. [PubMed: 8413457]

84. Burrows RF, Kelton JG. Thrombocytopenia at delivery: a prospective survey of 6715 deliveries. Am J Obstet Gynecol 1990;162(3):731. [PubMed: 2316579]

85. Matthews JH, Benjamin S, Gill DS, et al. Pregnancy-associated thrombocytopenia: definition, incidence and natural history. Acta Haematol 1990;84(1):24. [PubMed: 2117324]

86. Cunningham FG, Lindheimer MD. Hypertension in Pregnancy. N Engl J Med 1992;326(14):927. [PubMed: 1542342]

87. Lindheimer MD, Katz AI. Hypertension in pregnancy. N Engl J Med 1985;313(11):675. [PubMed: 3894964]

88. Rauramo L. The incidence of eclampsia in Finland, 1927 -1958. Pathol Microbiol 1961;24:435. [PubMed: 14490589]

89. Sibai BM. Diagnosis and management of gestational hypertension and preeclampsia. Obstet Gynecol 2003;102(1):181. [PubMed: 12850627]

90. Esplin MS, Fausett MB, Fraser A, et al. Paternal and maternal components of the predisposition to preeclampsia. N Engl J Med 2001;344(12):867. [PubMed: 11259719]

91. Romero R, Duffy TP. Platelet disorders in pregnancy. Clin Perinatol 1980;7(2):327. [PubMed: 7002423]

92. Romero R, Lockwood C, Oyarzun E, et al. Toxemia: new concepts in an old disease. Semin Perinatol 1988;12(4):302. [PubMed: 3065943]

93. Redman CW. Current topic: pre-eclampsia and the placenta. Placenta 1991;12(4):301. [PubMed: 1946241] 
94. Lindheimer MD, Katz AI. Preeclampsia: pathophysiology, diagnosis, and management. Annu Rev Med 1989;40:233. [PubMed: 2658750]

95. Brosens I, Dixon HG, Robertson WB. Fetal growth retardation and the arteries of the placental bed. Br J Obstet Gynaecol 1977;84(9):656. [PubMed: 911717]

96. De Wolf F, Brosens I, Renaer M. Fetal growth retardation and the maternal arterial supply of the human placenta in the absence of sustained hypertension. Br J Obstet Gynaecol 1980;87(8):678. [PubMed: 7426529]

97. Meekins JW, Pijnenborg R, Hanssens M, et al. A study of placental bed spiral arteries and trophoblast invasion in normal and severe pre-eclamptic pregnancies. Br J Obstet Gynaecol 1994;101(8):669. [PubMed: 7947500]

98. Zhou Y, Damsky CH, Chiu K, et al. Preeclampsia is associated with abnormal expression of adhesion molecules by invasive cytotrophoblasts. J Clin Invest 1993;91(3):950. [PubMed: 7680671]

99. Bussolino F, Benedetto C, Massobrio M, et al. Maternal vascular prostacyclin activity in preeclampsia. Lancet 1980;2(8196):702. [PubMed: 6106815]

100. Geary M. The HELLP syndrome. Br J Obstet Gynaecol 1997;104(8):887. [PubMed: 9255078]

101. Karumanchi SA, Maynard SE, Stillman IE, et al. Preeclampsia: a renal perspective. Kidney Int 2005;67(6):2101. [PubMed: 15882253]

102. Magann EF, Martin JN Jr. Twelve steps to optimal management of HELLP syndrome. Clin Obstet Gynecol 1999;42(3):532. [PubMed: 10451769]

103. Audibert F, Friedman SA, Frangieh AY, et al. Clinical utility of strict diagnostic criteria for the HELLP (hemolysis, elevated liver enzymes, and low platelets) syndrome. Am J Obstet Gynecol 1996;175(2):460. [PubMed: 8765269]

104. Padden MO. HELLP syndrome: recognition and perinatal management. Am Fam Physician 1999;60 (3):829. [PubMed: 10498110]

105. Stone JH. HELLP syndrome: hemolysis, elevated liver enzymes, and low platelets. JAMA 1998;280 (6):559. [PubMed: 9707148]

106. Weinstein L. Syndrome of hemolysis, elevated liver enzymes, and low platelet count: a severe consequence of hypertension in pregnancy. Am J Obstet Gynecol 1982;142(2):159. [PubMed: 7055180]

107. Sibai BM. The HELLP syndrome (hemolysis, elevated liver enzymes, and low platelets): much ado about nothing? Am J Obstet Gynecol 1990;162(2):311. [PubMed: 2309811]

108. Thiagarajah S, Bourgeois FJ, Harbert GM Jr, et al. Thrombocytopenia in preeclampsia: associated abnormalities and management principles. Am J Obstet Gynecol 1984;150(1):1. [PubMed: 6476014]

109. Ridolfi RL, Bell WR. Thrombotic thrombocytopenic purpura. Report of 25 cases and review of the literature. Medicine (Baltimore) 1981;60(6):413. [PubMed: 7031412]

110. Sibai BM. Imitators of severe pre-eclampsia/eclampsia. Clin Perinatol 2004;31(4):835. [PubMed: 15519430]

111. Levy GG, Nichols WC, Lian EC, et al. Mutations in a member of the ADAMTS gene family cause thrombotic thrombocytopenic purpura. Nature 2001;413(6855):488. [PubMed: 11586351]

112. Mayer SA, Aledort LM. Thrombotic microangiopathy: differential diagnosis, pathophysiology and therapeutic strategies. Mt Sinai J Med 2005;72(3):166. [PubMed: 15915311]

113. Furlan M, Robles R, Galbusera M, et al. von Willebrand factor-cleaving protease in thrombotic thrombocytopenic purpura and the hemolytic-uremic syndrome. N Engl J Med 1998;339(22):1578. [PubMed: 9828245]

114. Sanchez-Luceros A, Farias CE, Amaral MM, et al. von Willebrand factor-cleaving protease (ADAMTS13) activity in normal non-pregnant women, pregnant and post-delivery women. Thromb Haemost 2004;92(6):1320. [PubMed: 15583740]

115. Tsai HM, Lian EC. Antibodies to von Willebrand factor-cleaving protease in acute thrombotic thrombocytopenic purpura. N Engl J Med 1998;339(22):1585. [PubMed: 9828246]

116. Karmali MA, Petric M, Lim C, et al. The association between idiopathic hemolytic uremic syndrome and infection by verotoxin-producing Escherichia coli. J Infect Dis 1985;151(5):775. [PubMed: 3886804] 
117. McCrae, KR.; Sadler, JE.; Cines, DB. Thrombotic thrombocytopenic purpura and the hemolytic uremic syndrome. In: Hoffman, R.; Benz, EJJ.; Shattil, SJ., editors. Hematology: Basic Principles and Practice. Philadelphia: Elsevier,Churchill, Livingstone; 2005. p. 2287

118. Bick RL. Disseminated intravascular coagulation and related syndromes: a clinical review. Semin Thromb Hemost 1988;14(4):299. [PubMed: 3057630]

119. Ratnoff OD, Pritchard JA, Colopy JE. Hemorrhagic states during pregnancy. N Engl J Med 1955;253 (3):97. [PubMed: 14394335]

120. Purdie FR, Nieto JM, Summerson DJ, et al. Rupture of the uterus with DIC. Ann Emerg Med 1983;12 (3):174. [PubMed: 6829998]

121. Bick RL. Syndromes of disseminated intravascular coagulation in obstetrics, pregnancy, and gynecology. Objective criteria for diagnosis and management. Hematol Oncol Clin North Am 2000;14(5):999. [PubMed: 11005032]

122. Knox TA, Olans LB. Liver disease in pregnancy. N Engl J Med 1996;335(8):569. [PubMed: 8678935]

123. Abramowicz JS, Sherer DM, Woods JR Jr. Acute transient thrombocytopenia associated with cocaine abuse in pregnancy. Obstet Gynecol 1991;78(3 Pt 2):499. [PubMed: 1870806]

124. Gimovsky ML, Montoro M. Systemic lupus erythematosus and other connective tissue diseases in pregnancy. Clin Obstet Gynecol 1991;34(1):35. [PubMed: 2025975]

125. Budman DR, Steinberg AD. Hematologic aspects of systemic lupus erythematosus Current concepts. Ann Intern Med 1977;86(2):220. [PubMed: 835948]

126. Weiner CP. The mechanism of reduced antithrombin III activity in women with preeclampsia. Obstet Gynecol 1988;72(6):847. [PubMed: 3186090]

127. Schiff E, Peleg E, Goldenberg M, et al. The use of aspirin to prevent pregnancy-induced hypertension and lower the ratio of thromboxane A2 to prostacyclin in relatively high risk pregnancies. $\mathrm{N}$ Engl J Med 1989;321(6):351. [PubMed: 2664522]

128. Cunningham FG, Gant NF. Prevention of preeclampsia--a reality? N Engl J Med 1989;321(9):606. [PubMed: 2761603]

129. Lockwood CJ, Peters JH. Increased plasma levels of ED1+ cellular fibronectin precede the clinical signs of preeclampsia. Am J Obstet Gynecol 1990;162(2):358. [PubMed: 2309814] 


\section{Table 1}

Causes of Pregnancy-Associated Thrombocytopenia

\begin{tabular}{|c|c|}
\hline Isolated thrombocytopenia & Thrombocytopenia associated with systemic disorders \\
\hline Gestational (incidental) & $\begin{array}{ll}\text { - } & \text { Microangiopathic } \\
\text { - } & \text { Preeclampsia } \\
\text { - } & \text { HELLP syndrome } \\
\text { - } & \text { HUS } \\
\text { - } & \text { TTP } \\
\text { - } & \text { Disseminated Intravascular Coagulation } \\
\text { - } & \text { Acute fatty liver of pregnancy }\end{array}$ \\
\hline Immune (ITP) & 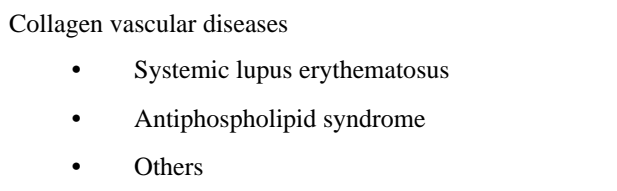 \\
\hline $\begin{array}{l}\text { Drug Induced } \\
\text { - HIT (with or without thrombosis) }\end{array}$ & $\begin{array}{c}\text { Viral infections } \\
\begin{array}{cc}\text { - } & \text { HBV } \\
\bullet & \text { EBV } \\
\text { - } & \text { CMV }\end{array}\end{array}$ \\
\hline $\begin{array}{l}\text { Inherited } \\
\text { Type Iib von Willebrand disease }\end{array}$ & $\begin{array}{l}\text { Nutritional deficiencies } \\
\text { Hypersplenism } \\
\text { Bone marrow dysfunction }\end{array}$ \\
\hline
\end{tabular}

Abbreviations: ITP, immune thrombocytopenia; HIT, heparin induced thrombocytopenia; HUS, hemolytic uremic syndrome; TTP, thrombotic thrombocytopenic purpura; HBV, hepatitis B virus; EBV, Epstein - Barr virus; CMV, cytomegalovirus. 
Table 2

Medical Management of ITP in Pregnancy - ASH and BCSH Guidelines

\begin{tabular}{|c|c|c|c|}
\hline & ASH & BCSH & \\
\hline Treatment Indications & $\begin{array}{ll}\cdot & \text { Platelets }<10,000 / \mu \mathrm{L} \\
\text { - } & \text { Platelets } 10,000-30,000 / \mu \mathrm{L} \text { in } 2^{\text {nd }} \text { or } 3^{\text {rd }} \text { trimester bleedin }\end{array}$ & • & $\begin{array}{l}\text { Platelets }<20,000 / \mu \mathrm{L} \text {, unless deliver } \\
\text { imminent }\end{array}$ \\
\hline IVIg & $\begin{array}{ll}\text { - } & \text { Initial Treatment: } 3^{\text {rd }} \text { trimester and platelets }<10,000 / \mu \mathrm{L} \\
\text { - } & \text { Initial treatment: patelets } 10,000-30,000 / \mu \mathrm{L} \text { and bleedin } \\
\text { - } & \text { After steroid failure: platelets }<10,000 / \mu \mathrm{L} \\
\text { - } & \text { After steroid failure: platelets } 10,000-30,000 / \mu \mathrm{L} \text { and } \\
\text { bleeding } \\
\text { - } \\
\text { After steroid failure: } 3^{\text {rd }} \text { trimester, platelets } 10,000- \\
30,000 / \mu \mathrm{L} \text {, asymptomatic }\end{array}$ & $\bullet$ & $\begin{array}{l}\text { Oral corticosteroids and IVIg have similar } \\
\text { responses as in non pregnant state }\end{array}$ \\
\hline Splenectomy & $2^{\text {nd }}$ trimester, platelets $<10,000 / \mu \mathrm{L}$, bleeding & & $\begin{array}{l}\text { If essential, in the second trimester. } \\
\text { Laparoscopic approach advantageous }\end{array}$ \\
\hline $\begin{array}{l}\text { Safe platelet count for } \\
\text { delivery }\end{array}$ & - $\quad 50,000 / \mu \mathrm{L}$ & $\bullet$ & $\begin{array}{l}\text { Vaginal delivery: } 50,000 / \mu \mathrm{L} \\
\text { Cesarean section: } 80.000 / \mu \mathrm{L} \\
\text { Epidural anesthesia: } 80,000 / \mu \mathrm{L}\end{array}$ \\
\hline
\end{tabular}

Abbreviations: ITP, immune thrombocytopenia; ASH, American Society of Hematology; BSCH, British Committee for Standards in Haematology; IVIg, intravenous immune-globulin. 
Table 3

Management of Delivery in Patients with Pregnancy Associated ITP - ASH and BCSH Guidelines

\begin{tabular}{|c|c|c|c|c|}
\hline & ASH & & BCSH & \\
\hline Cordocentesis or fetal scalp sampling & & $\begin{array}{l}\text { - } \\
\text { - } \quad \text { Unnecessary in women without known ITP }\end{array}$ & $\cdot$ & Not recommended \\
\hline Cesarean section & & $\begin{array}{l}\text { - } \quad \text { In selected circumstances } \\
\text { - } \\
\text { - } \\
\text { - } \quad \text { Not indicated if fetal platelet count unknown } \\
\text { Not indicated if maternal platelet count }>50,000 / \mu \mathrm{L}\end{array}$ & $\bullet$ & Obstetric indications only \\
\hline Safe platelet count ff delivery & & $\begin{array}{l}\text { - } \quad \text { Vaginal delivery: } 50,000 / \mu \mathrm{L} \\
\text { - } \quad \text { Cesarean section: } 50,000 / \mu \mathrm{L}\end{array}$ & & $\begin{array}{l}\text { Vaginal delivery: } 50,000 / \mu \mathrm{L} \\
\text { Cesarean section: } 80.000 / \mu \mathrm{L} \\
\text { Epidural anesthesia: } 80,000 / \mu \mathrm{L}\end{array}$ \\
\hline
\end{tabular}

Abbreviations: ITP, immune thrombocytopenia; ASH, American Society of Hematology; BSCH, British Committee for Standards in Haematology; IVIg, intravenous immune-globulin. 


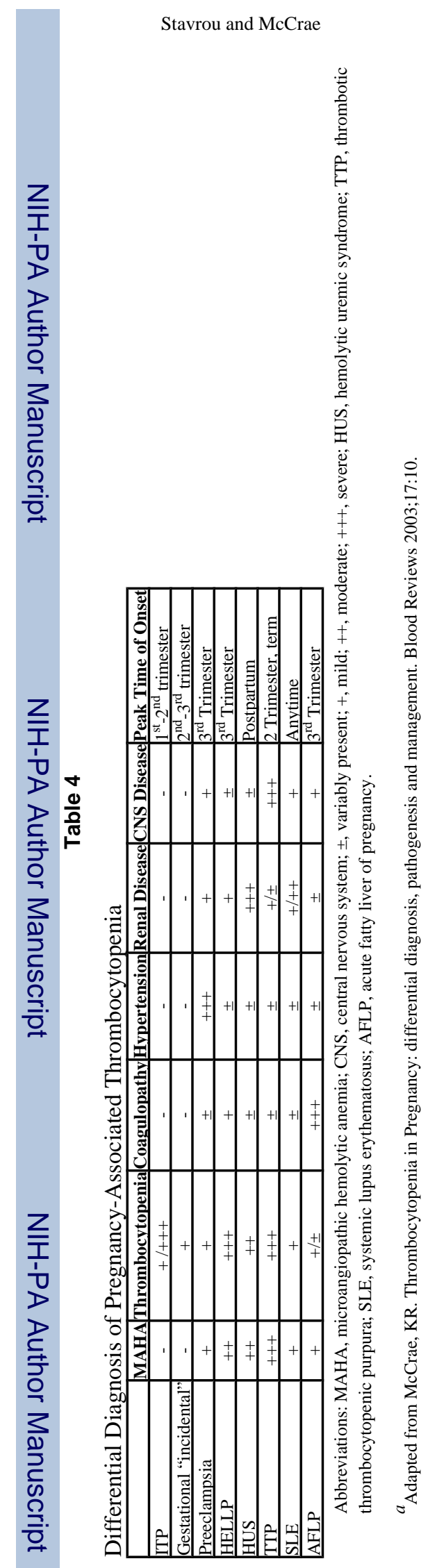

Page 19

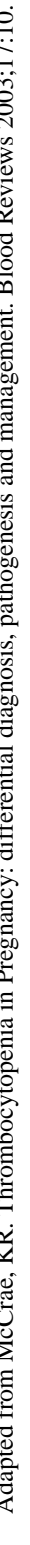

Hematol Oncol Clin North Am. Author manuscript; available in PMC 2010 December 1. 